\title{
A comparative study on prevention of ventilator associated pneumonia using endotracheal tube with or without intermittent subglottic secretion drainage device
}

\author{
Mohammad Asaduzzaman ${ }^{1}$, Mohammad Omar Faruq ${ }^{2}$, ASM Areef Ahsan 3 , Kaniz Fatema ${ }^{4}$, Fatema Ahmed ${ }^{4}$, \\ Uzzwal Kumar Mallick ${ }^{5}$, Amina Sultana ${ }^{6}$, Md. Motiul Islam7, Silfat Azam ${ }^{8}$, Masud Kabir ${ }^{8}$, Jannatul Ferdous ${ }^{9}$
}

\begin{abstract}
Context: Ventilator-associated pneumonia (VAP) causes substantial morbidity and mortality. The influence of intermittent subglottic secretion drainage (SSD) in preventing VAP has been supported by literature studies.

Objective: To find out the effectiveness of subglottic secretion drainage (SSD) on prevention of ventilator associated pneumonia (VAP) using endotracheal tube with subglottic secretion drainage (ETT-SSD).

Methodology: This study was carried out in the 10 beded medical-care Intensive Care Unit (ICU) of BIRDEM Hospital, Dhaka over a period of one and half year, enrolling 48 subjects. Patients expected to require mechanical ventilation $(M V)$ for more than $>48$ hrs were randomly assigned to one of two groups: one was ventilated with ETT-SSD and the other with conventional endotracheal tube (ETT-C).

Results: Primary outcome was the overall incidence of VAP based on quantitative culture of distal pulmonary samplings performed after each clinical suspicion. Other outcomes included incidence of early and late onset $V A P$, duration of $M V$, duration of ICU stay and in hospital mortality. Microbiologically confirmed VAP occurred in 23 patients, 6 of 24 (25\%) in the SSD group and 17 of 24 (70.83\%) in the control group.
\end{abstract}

Conclusion: The use of an ETT with intermittent SSD in a patient on MV helps to prevent ventilator associated pneumonia.

Keywords: Subglottic secretion drainage (SSD), ventilator-associated pneumonia (VAP)

\section{Introduction:}

Pneumonia is the number one cause of death from infectious diseases world wide. The patient with pneumonia is managed in the intensive care unit (ICU) when severe forms of community-acquired pneumonia (CAP) are present or when a hospitalized patient develops a life threatening nosocomial pneumonia (NP). In the ICU almost $90 \%$ of episodes of NP occur in patients who are being mechanically ventilated for other reasons, and this is termed ventilator-associated pneumonia (VAP). In all forms of severe pneumonia, antibiotic resistance is an increasing problem, especially among pneumococci in CAP, and with Pseudomonas aeruginosa, Acinetobacter spp., extended-spectrum $\beta$-lactamase-producing gram-negatives, and methicillin-resistant Staphylococcus aureus(MRSA) in VAP and $\mathrm{HCAP}^{1,2}$

Ventilator-associated pneumonia (VAP) is defined as a pneumonia occurring in intubated or tracheostomized patients undergoing mechanical ventilation. Usual guidelines suggest a delay of 48 to 72 hours between the beginning of mechanical ventilation $\&$ the occurrence of pneumonia to qualify for this diagnosis. ${ }^{3}$ Pneumonia resultant to the entry of bacteria into the normally sterile lower respiratory tract, leading to colonization \& subsequently to infection when bacteria overwhelm host defenses secondary to a large bacterial inoculum, a virulent pathogen, or a defect in the local host defenses ${ }^{4,5}$.
Bacteria can reach the lower respiratory tract by four different pathogenic mechanisms: (a) contiguous spread, (b) hematogenous spread, (c) inhalation, \& (d) aspiration. The first two mechanisms of invasion are infrequent. ${ }^{6}$ Inhalation of gastric material or direct inoculation of bacteria into the lower respiratory tract through contaminated "devices" (aerosol, bronchoscopes, ventilator circuit, nebulizer, tracheal suctioning) are rarely associated with VAP. Aspiration of bacteria colonizing the oropharynx is the main route of entry into the lower respiratory tract.

Colonization of the oropharyngeal airways by pathogenic micro-organisms occurs during the first hospital week in most critically ill patients. These micro-organisms that replace the normal microflora of the oropharynx can be either endogenous (enteric Gram-negative bacteria) or exogenous via a cross-contamination from other patients in the ICU. The stomach, sinuses, \& dental plaque may be potential reservoirs for pathogens colonizing the oropharynx. However, their exact contribution still remains controversial. The endotracheal tube compromises the natural barrier between the oropharynx \& lower respiratory tract \& leakage of contaminated secretions around the ETT cuff allows bacterial entry into the trachea. ${ }^{4,5}$ Many risk factors for VAP are host related \& thus not accessible to interventions include male gender, pre-existing pulmonary disease, coma, AIDS, head trauma, age $>60$ years, neurosurgical procedures \& multi-organ system failure. ${ }^{7}$ 
Bangladesh Crit Care J March 2018; 6 (1): 7-15

Among accessible risk factors, the most important is the presence of mechanical ventilation, associated with a 3 to 21 -fold risk. ${ }^{8}$ The conventional ETT limits the draining of secretions that leak around the cuff, favors bacterial multiplication, offers a focus for bacterial adherence \& colonization \& impairs ciliary clearance \& cough. Furthermore, the mechanically ventilated patient requires other devices such as nebulizers or humidifiers, which can be a source of micro-organisms. The risk of infection is highest during the first 8 to 10 days of mechanical ventilation ${ }^{9} \&$ increases with the duration of mechanical ventilation ${ }^{10}$.

Accidental extubation, rather than re-intubation, increases the risk of $\mathrm{VAP}^{11}$, likely due to preparation for extubation that is obviously inadequate to nonexistent. Enteral nutrition administered by a nasogastric (NG), rather than a post-pyloric tube also increases the risk of VAP. ${ }^{7,10}$ The NG tube might increase the risk of reflux \& subsequent colonization of the airways. Other factors facilitating the inhalation of oropharyngeal secretions favor VAP: supine position, patient transportation out of the $\mathrm{ICU}^{12}$, sedation ${ }^{13}$, failed subglottic aspiration $^{9}$, intra-cuff pressure $<20 \mathrm{cmH}_{2} \mathrm{O}$, tracheostomy, \& aerosol treatment. Identifying these risk factors will guide the preventive measures of VAP.

In early-onset VAP, the main causative pathogens are S. pneumoniae, methicillin-susceptible S. aureus, H. influenzae, \& susceptible Gram-negative enteric bacilli. ${ }^{14}$ In late-onset VAP, MRSA, P. aeruginosa, A. baumannii, \& S. maltophilia are the main causative organisms.

1. Assistant Registrar, Department of Critical Care Medicine National Institute of Neurosciences and Hospital (NINSH), Sher e Bangla Nagar, Agargaw, Dhaka, 1207

2. Professor of Critical Care Medicine and Consultant of ICU, United Hospital, Gulshan 2, Dhaka.

3. Professor of Critical Care Medicine, BIRDEM General Hospital

4. Associate Professor of Critical Care Medicine, BIRDEM General Hospital

5. Registrar, Department of Critical Care Medicine, NINSH, Sher e Bangla Nagar, Agargaw, Dhaka, 1207

6. Intensivist, General ICU, United Hospital, Gulshan 2, Dhaka.

7. Associate Consultant, Medical ICU, Asgar Ali Hospital., Distillary Road, Gandaria, Dhaka-1204.

8. Medical officer, Department of Critical Care Medicine, National Institute of Neurosciences and Hospital (NINSH), Sher e Bangla Nagar, Agargaw, Dhaka, 1207

9. Lecturer in Bangladesh Health Professional Institute, CRP, Savar.

\section{Corresponding Author:}

Dr. Mohammad Asaduzzaman MBBS, MD (Critical Care Medicine)

Assistant Registrar, Department of Critical Care Medicine

National Institute of Neurosciences and Hospital (NINSH)

Sher e Bangla Nagar, Agar Gao, Dhaka, 1207

Email: dr_asad2011@yahoo.com

Phone: +8801711903279
In the ICU, the diagnosis of VAP remains a challenge; the diagnostic approach is based on two successive steps: (a) the diagnosis of pneumonia must be established and (b) the etiologic pathogen(s) of this pulmonary parenchyma infection must be identified. ${ }^{4}$ Pneumonia is suspected when a patient exhibits signs and symptoms suggesting both pulmonary involvement and infection. The most current signs of infection are fever or hypothermia, leukocytosis or leucopenia, and tachycardia. Purulent sputum, a decline in oxygenation, and pulmonary infiltrates on chest radiograph are suggestive of pulmonary involvement.

Screening for VAP was maintained until the first episode of microbiologically confirmed VAP, or 48 hours after weaning from the ventilator, or death, or Day 28 of mechanical ventilation, whichever occurred first.

Despite the use of a wide range of preventive measures, VAP continues to complicate the course of $9-27 \%$ of patients receiving mechanical ventilation in the ICU \& remains an important cause of morbidity and mortality. ${ }^{5,15}$ Aspiration of oro-pharyngeal pathogens \& leakage of subglottic secretions containing bacteria around the endotracheal tube cuff are the primary routes of bacterial entry into the lower respiratory tract. ${ }^{16-19}$ Subglottic secretion drainage (SSD), using a specially designed endotracheal tube with a separate dorsal lumen that opens immediately above the endotracheal cuff, has been developed to prevent the occurrence of VAP.

Critically ill patients who require mechanical ventilation are at risk for ventilator associated pneumonia. The data obtained from this study may guide the physician focusing about preventive role of SSD over VAP as well as cost effectiveness by reducing ventilator time, related complication \& ICU stay. Further findings of the research may provide useful information to the government and non-government authorities for formulating guidelines for the prevention of VAP.

\section{Materials and Method :}

This prospective observational study was carried out in Intensive Care Unit in the department of Critical Care Medicine, BIRDEM Hospital, Dhaka over a period of 16 months starting from January 2012 to April 2013. All consecutive patients expected to require mechanical ventilation for more than 48 hours were randomly assigned to one of two groups: one was intubated with a specific endotracheal tube allowing the drainage of subglottic secretions (Hi-Lo ${ }^{\mathrm{TM}}$ Evac ETT with SSD (Figure 1). Brand name of Tyco Healthcare) and the other with conventional ETT (Figure 2). All adults aged 18 years or more and willing to participate in the study were considered for inclusion. The following enrollment criteria were employed to select the required number of population. 


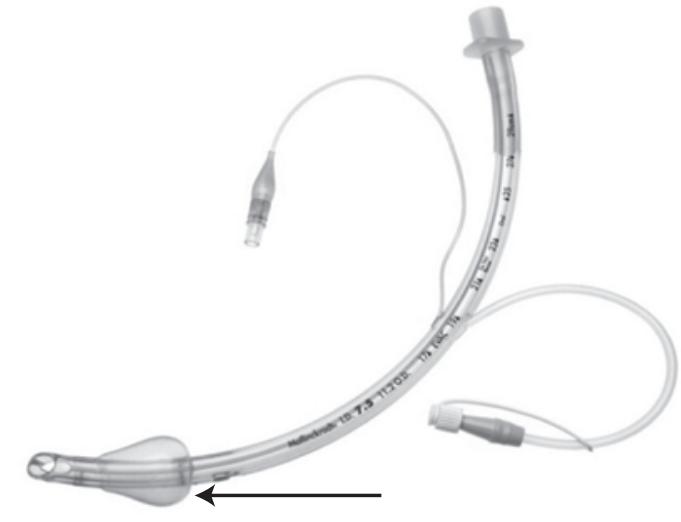

Fig 1: HI--Lo Evac ETT with dorsal lumen with opening for SSD (arrow)

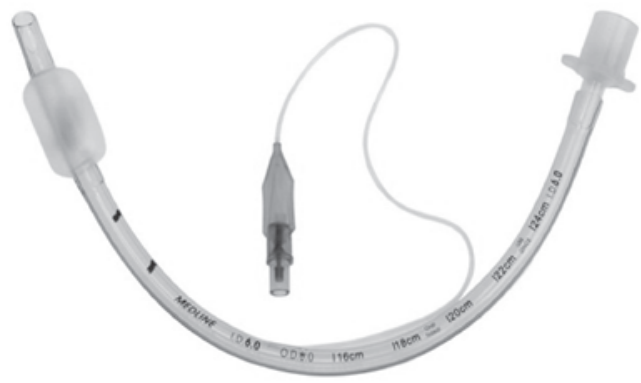

Fig 2 : Conventional ETT without dorsal lumen

Inclusion criteria for study subjects were as follows.

1) Age $>18$ years

2) Presence of a new or progressive pulmonary infiltrate associated with at least two of the following three infectious signs: fever greater than $38^{\circ} \mathrm{C}$, leukocytosis or leucopenia, and/or purulent secretions.

3) Time interval $>48$ hours after placement on mechanical ventilator till Day 28

4) For patients with ARDS, hemodynamic instability and/or deterioration of blood gases could be considered to suspect VAP.

5) 48 hours after weaning from the ventilator.

6) First episode of VAP if patient has recurrent VAP during stay in ICU

Exclusion criteria for the study subjects were as follows.

1) Age $<18$ years

2) Time interval of onset of pneumonia $<48$ hours after placement on mechanical ventilator.

3) Patient on NIPPV (Non invasive positive pressure ventilation)

4) $\geq$ Day 28 of mechanical ventilation

5) Recurrent VAP on same hospital admission after first episode

6) Patient intubated from outside hospital
It was assured that all records would be kept confidential and the study would be helpful for the physicians in the prevention and management of pneumonia case on ventilator in future. Informed written consent was obtained from the attendants/local guardians of the patients who voluntarily consented to allow their patients to include in the study. The study commenced on obtaining approval from the Ethical Review Committee. 48 patients were feasible to be included due to time limitation.

Equipments and accessories required to perform the study were conventional endotracheal tube, endotracheal tube with subglottic secretion drainage (Hi-Lo Evac ETT), Specimen Trap (Busse brand, made in USA), suction catheter, and mechanical ventilator (MV). The materials used in the study were normal saline, $10 \mathrm{cc}$ syringe.

Hourly subglottic secretion drainage was carried out in every patient on ETT with SSD. Regular VAP surveillance was carried out throughout the period of patients on MV and two days after extubation by clinical, radiological and biochemical screening including rectal temperature, blood pressure, total WBC count, portable chest X-ray etc.

Endotracheal aspirate was collected under aseptic precautions using sterile suction catheters and traps. The presence of epithelial cells of $>10 \%$ implied contamination of the specimen whilst $<10 \%$ neutrophils suggested that the diagnosis of pneumonia was less likely. With quantitative analysis of ETA, threshold for diagnosis of pneumonia in this study was taken as $10^{5}$ colony forming units $/ \mathrm{ml}(\mathrm{CFU} / \mathrm{ml})$. The sample was sent immediately for culture.

When there was multiple culture positivity of a sample with different type of organisms, three consecutive morning respiratory samples were sent to detect the contaminated sample.

\section{Results:}

In the present study a total of 48 mechanically ventilated patients admitted in the intensive care unit (ICU) of BIRDEM were selected on the basis of selection criteria. All ventilated patients for more than 48 hours, who were intubated either by Hi-Lo ${ }^{\mathrm{TM}}$ Evac ETT or by conventional ETT, were selected consecutively. In the SSD group, subglottic secretions were suctioned manually with a $10 \mathrm{ml}$ syringe at an intended frequency of single suction per hour. All those patients were followed up till 28 days or death after they met the criteria for VAP, or till their death or improvement to leave the ICU. The findings obtained from data analysis are presented below.

Table- 1 shows the age distribution of the study subjects. The patients were predominantly elderly with age $>60$ years $(58.33 \%)$, followed by $51-60$ years $(16.6 \%), 41-50$ years $(12.5 \%), \leq 30$ years $(8.33 \%)$ and $31-40$ years $(4.16 \%)$. The mean age of the patients was $60.10 \pm 15.4$ with median 62.50 and mode 65 . The youngest and the oldest patients were 20 and 80 years old respectively. 
Table-1:

\begin{tabular}{lcc}
\hline Age (years) & Frequency & Percentage \\
\hline$\leq 30$ & 04 & 8.33 \\
$31-40$ & 02 & 4.16 \\
$41-50$ & 06 & 12.5 \\
$51-60$ & 08 & 16.6 \\
$>60$ & 28 & 58.33 \\
\hline
\end{tabular}

Mean age $=60.10 \pm 15.4$; Range $=20-80$ years

Baseline hemodynamic state, total count of WBC, blood $\mathrm{c}$ and partial pressure of oxygen are illustrated in Table-II. mean values of systolic and diastolic pressures, heart respiratory rate and temperature indicate that most of patients were hemodynamically stable. The mean value GCS indicates that most of the ICU admitted patients v need MV were in altered conscious state. The mean partial pressure of oxygen $\left(\mathrm{PaO}_{2}\right)$ value was highly satisfactory. The mean total WBC count was much higher than the upper limit of normal range. The mean blood urea level was high indicates kidney injury is common in ICU admitted patient requiring $\mathrm{MV}$.

Quantitative culture of blind tracheal aspirate / BAL showed a significant growth $\left(\geq 10^{5} \mathrm{CFU} / \mathrm{ml}\right)$ of microbes in 26 patients out of 48 . Blood culture was positive among 8 study patient and urine culture in 17 study patients which are showed in Fig III.

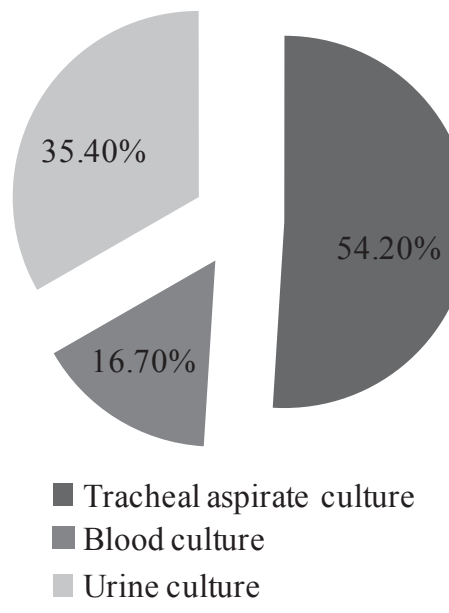

Fig III:

Pattern of micro-organism grown on culture of tracheal aspirate or BAL(Broncho-alveolar lavage) during admission is shown in Fig IV.

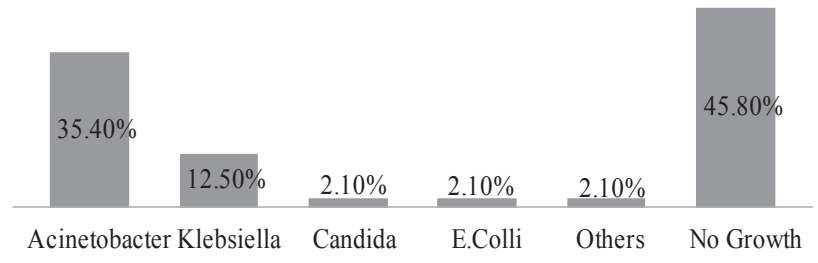

Fig IV:
Acinetobacter sp. was the predominant organism isolated from respiratory secretion $(35.40 \%)$ followed by Klebsiella $(12.5 \%)$. Candida $(2.1 \%)$ and E. Colli $(2.1 \%)$ were the least grown organism. S. aureus was rarely found.

Figure V shows, out of 48 study patients 39 patients had pneumonia as initial diagnosis, 28 patients had acute kidney injury and 25 patients were in septic shock

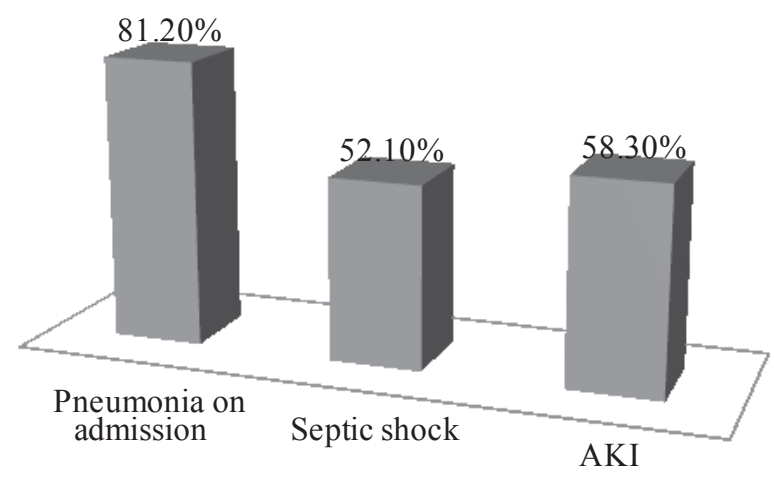

Fig-V:

Common organism isolated from tracheal aspirate from VAP patients are shown in Fig VI

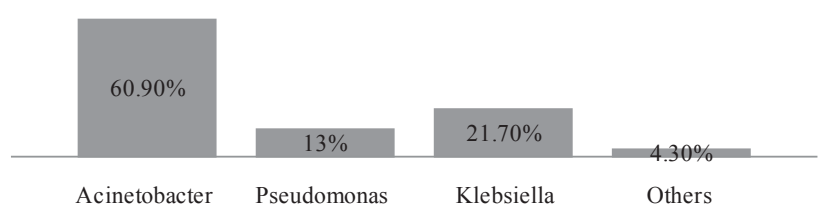

Fig VI :

Among the 48 study patients 24 patients were intubated with conventional ETT and the rest half were intubated with Hi-Lo evac ETT randomly. Amongst them 23 patients (47.9\%) developed VAP. Out of 23 patients 17 were ventilated through conventional ETT and 6 patients were ventilated through Hi-Lo evac ETT (Fig:VII).

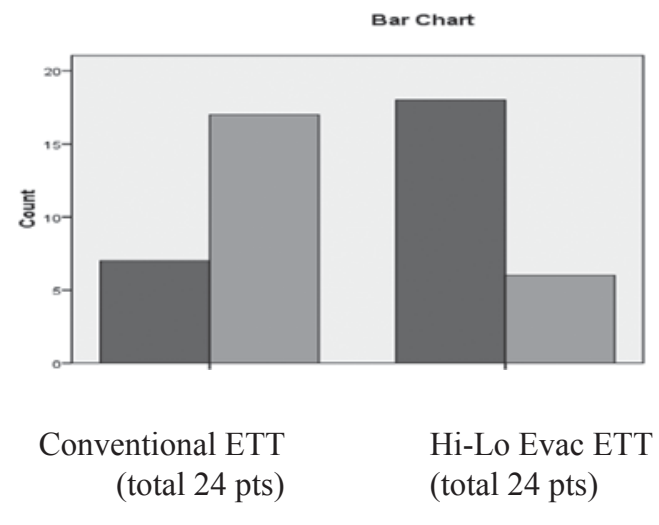

Fig-VII: 
Table II:

\begin{tabular}{lccccccc}
\hline $\mathrm{n}=48$ & $\begin{array}{c}\text { VAP Day1 } \\
\text { MBP } \\
(\mathbf{m m H g})\end{array}$ & $\begin{array}{c}\text { VAP Day1 } \\
\text { Heart rate } \\
\text { (beat/min) }\end{array}$ & $\begin{array}{c}\text { VAP Day1 } \\
\text { RR } \\
\text { (breath/min) }\end{array}$ & $\begin{array}{c}\text { VAP Day1 } \\
\text { TEMP }\left({ }^{\mathbf{C}} \mathbf{C}\right)\end{array}$ & $\begin{array}{c}\text { VAP Day1 } \\
\text { GCS (3-15) CBC (cu/mm) }\end{array}$ & $\begin{array}{c}\text { VAP Day1 } \\
\text { Blood Urea } \\
(\mathbf{m g} / \mathbf{d l})\end{array}$ \\
\hline Mean & $80 \pm 25.37229$ & $119 \pm 14.89343$ & $24 \pm 6.34483$ & $102 \pm 1.65601$ & $8 \pm 3.15$ & $21233 \pm 8352$ & $124 \pm 67.93$ \\
Range & $42--130$ & $93--146$ & $15--44$ & $99--104$ & $3--15$ & $9290--38500$ & $35--328$ \\
\hline
\end{tabular}

Table-III: shows occurrence of VAP against conventional EET and Hi Low Evac ETT

Table III (Cross tabulation)

\begin{tabular}{|c|c|c|c|c|c|}
\hline & & & \multicolumn{2}{|c|}{ Presence of VAP } & \multirow[b]{2}{*}{ Total } \\
\hline & & & no & yes & \\
\hline & Conventional & Count & 7 & 17 & 24 \\
\hline & & $\%$ within ETT type & $29.2 \%$ & $70.8 \%$ & $100.0 \%$ \\
\hline & & $\%$ within Presence of VAP & $28.0 \%$ & $73.9 \%$ & $50.0 \%$ \\
\hline & Hi-Lo Evac ETT & Count & 18 & 6 & 24 \\
\hline ETT & & \% within ETT type & $75.0 \%$ & $25.0 \%$ & $100.0 \%$ \\
\hline type & & $\%$ within Presence of VAP & $72.0 \%$ & $26.1 \%$ & $50.0 \%$ \\
\hline \multirow[t]{3}{*}{ Total } & Count & 25 & 23 & 48 & \\
\hline & \% within ETT type & $52.1 \%$ & $47.9 \%$ & $100.0 \%$ & \\
\hline & $\%$ of Total & $52.1 \%$ & $47.9 \%$ & $100.0 \%$ & \\
\hline
\end{tabular}

Table-IV: shows difference of duration of ICU stay between VAP and Non- VAP patient

TableIV

ICU Duration

\begin{tabular}{llcc}
\hline & & Mean & Std. Deviation \\
Cluster & 1 (non VAP) & 10.3600 & 7.08802 \\
\hline 2 (VAP) & 18.5652 & 16.94597 \\
& Combined & 14.2917 & 13.31286 \\
\hline
\end{tabular}

Table $\mathbf{V}$ : shows duration of ICU stay among early and late onset VAP patients $(\mathrm{n}=23)$

Table V

Type of VAP

Mean days

Cluster

1 (Excluded 2 patients)
2 (early VAP 13 patients)
3 (late VAP 8 patients)
Combined

Duration in ICU

$\begin{array}{cc}67.5000 & 4.94975 \\ 10.5385 & 4.66575 \\ 19.3750 & 7.55811 \\ 18.5652 & 16.94597\end{array}$


Bangladesh Crit Care J March 2018; 6 (1): 7-15

Table VI: shows duration of ICU stay among VAP and Non - VAP patients $(n=48)$. Here two patients are excluded due to very prolonged MV duration for other diseased state.

Table VI

\begin{tabular}{llcc}
\hline & & MV Duration & \\
\hline Cluster & 1 (non-VAP 25 patient) & Mean days & 5.96434 \\
& 2 (Excluded 2 patient) & 6.3600 & 4.24264 \\
& 3 (VAP 21 patient) & 9.6667 & 5.70380 \\
& Combined & 10.8542 & 13.17798 \\
\hline
\end{tabular}

Table-VII shows type of VAP and its relation to MV duration( $\mathrm{n}=23)$

Table VII

\begin{tabular}{llcc}
\hline & \multicolumn{1}{c}{ Type of VAP } & Mean & Total duration of MV \\
& & 67.0000 & Std. Deviation \\
\hline Cluster & 1 (Excluded 2 patients) & 7.6154 & 4.24264 \\
& 2 (early VAP 13 patients) & 13.0000 & 4.77037 \\
& 3 (late VAP 8 patients) & 14.6522 & 5.78174 \\
& Combined & 17.41371 \\
\hline
\end{tabular}

Table VIII shows early VAP is more than late VAP and early VAP is more common with conventional ETT.

Table-VIII :

\begin{tabular}{lccc}
\hline ETT type & Type of VAP & Total \\
\hline Conventional & 10 & late & 17 \\
Hi-Lo Evac & 4 & 7 & 6 \\
Total & 14 & 2 & 23 \\
\hline
\end{tabular}

Amongst 48 study patients 15 patients died, among them 12 patients (80\%) had VAP. Total 32 patients improved and discharged from ICU, out of them 11 patients (34.4\%) had VAP. One took discharge on request. Out of 23 VAP patients 52.2\% patients died compared to $12 \%$ death in non VAP patient.(Table IX)

Table-IX (Cross tabulation)

\begin{tabular}{|c|c|c|c|c|c|}
\hline & & & \multicolumn{3}{|c|}{ Presence of VAP } \\
\hline & & & NO & YES & Total \\
\hline \multirow[t]{12}{*}{ Outcome } & Death & Count & 3 & 12 & 15 \\
\hline & & $\%$ Within Outcome & $20.0 \%$ & $80.0 \%$ & $100.0 \%$ \\
\hline & & $\%$ Within Presence of VAP & $12.0 \%$ & $52.2 \%$ & $31.2 \%$ \\
\hline & & $\%$ of Total & $6.2 \%$ & $25.0 \%$ & $31.2 \%$ \\
\hline & Improve & Count & 21 & 11 & 32 \\
\hline & & $\%$ Within Outcome & $65.6 \%$ & $34.4 \%$ & $100.0 \%$ \\
\hline & & $\%$ Within Presence of VAP & $84.0 \%$ & $47.8 \%$ & $66.7 \%$ \\
\hline & & $\%$ of Total & $43.8 \%$ & $22.9 \%$ & $66.7 \%$ \\
\hline & DOR & Count & 1 & 0 & 1 \\
\hline & & $\%$ Within Outcome & $100.0 \%$ & $.0 \%$ & $100.0 \%$ \\
\hline & & $\%$ Within Presence of VAP & $4.0 \%$ & $.0 \%$ & $2.1 \%$ \\
\hline & & $\%$ of Total & $2.1 \%$ & $.0 \%$ & $2.1 \%$ \\
\hline
\end{tabular}




\section{Discussion:}

Ventilator associated pneumonia is a major problem for critically ill patient. Prevention of ventilator associated pneumonia remains the main challenge in ICU patient undergoing mechanical ventilator (MV). It has significant impact on length of hospital stay and outcome. Accurate diagnosis is very important for patient recovery, rational use of antibiotics, avoiding over treatment and associated drug resistance problem.

In this study, we found a reduction in the incidence of earlyand late-onset VAP in patients treated with an endotracheal tube with a lumen for subglottic secretion drainage as compared with a conventional endotracheal tube without subglottic secretion drainage. Moreover, the absolute risk reduction in our patients indicates that 45 occurrences of VAP could be avoided for every 100 patients treated by SSD. One strength of our study is the concealment of the allocation process, complete follow-up of included patients, the intention-to-treat analysis, and high compliance with the planned subglottic secretion drainage procedure. We also carefully ensured that potentially confounding factors, including compliance with preventive measures for VAP other than SSD in the participating centers, use of antibiotics, tracheal cuff pressure, recumbent position, use of oral chlorhexidine were equally distributed among the two groups.

It is necessary to remember that SSD has reduced the incidence of VAP in some studies ${ }^{9,20,21,27}$; but in other studies it has not decreased the incidence of $\mathrm{VAP}^{22,23}$. The meta-analysis on VAP prevention, published on 2001 concluded that SSD appeared to be effective in preventing early-onset VAP only. ${ }^{24}$ Our results confirm the protective effect of SSD on early-onset pneumonia in mechanically ventilated patients as well as late onset pneumonia.

Our finding of a protective role for SSD in late-onset VAP is consistent with a randomized trial assessing the simultaneous use of SSD and a new polyurethane cuff. ${ }^{26}$. However, the respective contribution of SSD and the new cuff material to the reduction in late-onset VAP was unclear. ${ }^{26}$ The noticeable finding of our study is the finding that ETT-SSD, besides preventing early-onset VAP, also prevents late-onset VAP. The meta-analysis by Dezfulian and coworkers ${ }^{25}$ concluded that SSD appears primarily to reduce early-onset VAP; however, it is not clear why it may not prevent late-onset VAP. Presumably, some of the VAP cases (perhaps those of later onset) that still occurred in that study were due to secretions slipping past the ETT cuff and the dorsal suction lumen. This tube, in theory, should prevent leakage long enough to permit it to pool around the dorsal lumen and be aspirated. It is possible that, when SSD is intermittent, there could be subglottic secretion leakage during the periods without suctioning; second, when SSD is continuous the suctioning port may sometimes be occluded because of suctioning of the tracheal mucosa, sometimes causing SSD failure and, subsequently, subglottic secretion leakage.

More generally, our finding supports the orotracheal aspiration pathway as an important patho-physiologic mechanism for both early- and late-onset VAP. In relation to the first potential advantage of the ETT-SSD, it is necessary to remember that initial low-volume, high-pressure (LVHP) cuffs required a pressure of more than $60 \mathrm{~cm} \mathrm{H} 2 \mathrm{O}$ to achieve a clinical seal, and that a pressure higher than $50 \mathrm{~cm} \mathrm{H} 2 \mathrm{O}$ may ultimately stop capillary mucosal blood flow; thus, they frequently induced tracheal injury after prolonged use. ${ }^{29}$ It is important to distinguish between the pressure inside the cuff and the pressure applied to the tracheal wall; the tracheal wall pressure at a given cuff volume has been calculated as the difference between intracuff pressures at that volume when the cuff is inflated inside the trachea and when it is inflated while suspended freely in air. ${ }^{30}$

Subglottic secretions accumulated above the endotracheal cuff may descend along the channels within the folds of the cuff wall to the lower respiratory tract. This progression is easier with HVLP than with LVHP cuffs ${ }^{17-19,27-28}$ and accordingly, the risk of VAP increases. In addition, in one study with anesthetized patients, increasing the pressure in the HVLP cuff beyond clinical seal, to $50 \mathrm{~cm} \mathrm{H} 2 \mathrm{O}$, did not prevent aspiration, possibly because of not being able to avoid the formation of dye-filled cuff folds. ${ }^{28}$

The use of SSD in our study substantially decreased the incidence of microbiologically confirmed VAP. Secondary end points, that is, mortality, and duration of mechanical ventilation and ICU stay, were also influenced by the use of SSD. The real impact of SSD on important patient outcomes could therefore be beneficial. Considering that VAP could be associated with an absolute excess mortality of 10 to $30 \% 0^{5}$ a prospective randomized trial of a preventive intervention resulting in an absolute $10 \%$ reduction in the rate of VAP could be expected to result in an ICU mortality reduction of only 1 to $3 \%$. For such a reduction to be statistically significant, and depending on the expected baseline mortality rate in the control group (from 20 to $40 \%$ ), a large number of patients (several thousands) would have to be included in each arm. It is therefore highly likely that future randomized controlled trials on VAP prevention will be effective to detect a beneficial effect on mortality.

The $70.8 \%$ VAP rate in our control group was relatively very high, in comparison to the $22.1 \%$ VAP rate in the control patients (also intubated with the Hi-Lo Evac tube as in our study) in a randomized trial assessing the simultaneous use of SSD and a new polyurethane cuff in patients ${ }^{26}$ despite lower severity score on admission and ICU mortality than in our study patients. Another factor that might influence the generalizability of our study results is that almost $50 \%$ of the patients who required mechanical ventilation in the ICU during the study period were not intubated with the Hi-Lo Evac tube. This resulted from the heterogeneous availability of the Hi-Lo Evac tube through all the pre- and in-hospital systems involved in emergency intubation of critically ill patients before ICU admission. Because many mechanically ventilated patients in the ICU worldwide are intubated before their admission to the ICU, exclusion of these patients from our study, as in previous trials of $\mathrm{SSD}^{20,21,23}$ would only poorly reflect daily life practice. 
Our study had some limitations. Most important limitation is the small number of study patients. Only one fifth of the planned number of patients had been included at the end of the planned study period. The number of patients excluded because of the use of another device than the Hi-Lo Evac tube for intubation before ICU admission was high. We did not perform the relationship between prior use of antibiotics and the incidence of VAP, because of random use of antibiotics in our country like other low income countries for lack of knowledge and legal protocol to purchase drugs without physician prescription which may result in the development of resistant organism and may impact on the overall outcome.

A further limitation is that the VAP diagnostic procedure was not invasive for all the study patient and we used blind tracheal aspirate samples for every patient; however, a randomized clinical trial found no significant differences in clinical outcomes and use of antibiotics when using a diagnostic strategy for ventilator associated pneumonia based on quantitative culture of bronchoalveolar lavage fluid and non-quantitative culture of endotracheal aspirate. ${ }^{3}$

\section{Conclusion:}

In conclusion, the results of this study demonstrated that intermittent subglottic secretion drainage significantly reduces the incidence of microbiologically confirmed VAP, including early as well as late-onset VAP, without any notable adverse events. These results should encourage ICU physicians to progressively integrate SSD into their VAP preventive measures and prompt physicians involved in pre-ICU care to use endotracheal tubes permitting SSD. Because the risk of VAP increases with length of mechanical ventilation, patients with prolonged ventilation are likely to benefit the most from SSD. In many circumstances it remains hard to identify patients who will require long-lasting mechanical ventilation. Therefore, one might consider adopting all these VAP prevention measures in every mechanically ventilated, critically ill patient. As the study was done on a small number of South Asian patients from a single center, we need to have a multicenter study involving much larger population to arrive at a definitive conclusion.

\section{References:}

1. Niederman MS, Mandell LA, Anzueto A. Guidelines for the management of adults with community-acquired lower respiratory tract infections: Diagnosis, assessment of severity, antimicrobial therapy and prevention. Am J RespirCrit Care Med 2001; 163:1730-1754.

2. Niederman MS, Craven DE, Bonten MJ. Guidelines for the management of adults with hospital acquired, ventilator-associated, and Health care-associated pneumonia. Am J RespirCrit Care Med $2005 ; 171: 388-416$.

3. The Canadian Critical Care Trials Group. A randomized trial of diagnostic techniques for ventilator associated pneumonia. $\mathrm{N}$ Engl $\mathrm{J}$ Med 2006; 355: 2619-2630

4. American Thoracic Society, Infectious Diseases Society of America. Guidelines for the management of adults with hospital-acquired, ventilator-associated, and healthcare-associated pneumonia. Am J RespirCrit Care Med. 2005; 171:388.
5. Chastre J, Fagon JY. Ventilator-associated pneumonia. Am J RespirCrit Care Med. 2002; 165:867-903.

6. Rello J, Diaz E, Rodriguez A. Advances in the management of pneumonia in the intensive care unit: review of current thinking. ClinMicrobiol Infect. 2005; 11(5):30.

7. Bonten MJ, Kollef MH, Hall JB. Risk factors for ventilator-associated pneumonia: from epidemiology to patient management. Clin Infect Dis. 2004; 38:1141.

8. Chevret S, Hemmer M, Carlet J. Incidence and risk factors of pneumonia acquired in intensive care units. Results from a multicenter prospective study on 996 patients. European Co-operative Group on Nosocomial Pneumonia. Intensive Care Med. 1993; 19:256.

9. Rello J, Sonora R, Jubert P. Pneumonia in intubated patients: role of respiratory airway care. Am J RespirCrit Care Med. 1996; 154:111-115.

10. Cook DJ, Walter SD, Cook RJ. Incidence of and risk factors for ventilator-associated pneumonia in critically ill patients. Ann Intern Med. 1998; 129:433.

11. deLassence A, Alberti C, Azoulay E. Impact of unplanned extubation and reintubation after weaning on nosocomial pneumonia risk in the intensive care unit: a prospective multicenter study. Anesthesiology. 2002; 97:148.

12. Kollef MH, von Harz B, Prentice D. Patient transport from intensive care increases the risk of developing ventilator-associated pneumonia. Chest. 1997; 112:765-773.

13. Kollef MH. Ventilator-associated pneumonia: a multivariate analysis. JAMA. 1993; 27:1965-1970.

14. Torres A, Carlet J. Ventilator-associated pneumonia. European Task Force on ventilator-associated pneumonia. EurRespir J. 2001; 17:1034.

15. Klompas M. Does this patient have ventilator-associated pneumonia? JA MA 2007; 297:1583-1593.

16. American Thoracic Society, Infectious Diseases Society of America. Guidelines for the management of adults with hospital-acquired, Ventilator-associated, and healthcare-associated pneumonia. Am J RespirCrit Care Me d 2005; 171:388-416.

17. Oikkonen M, Aromaa U. Leakage of fluid around low-pressure tracheal tube cuffs. Anaesthesia 1997; 52:567-569.

18. Petring OU, Adelhoj B, Jensen BN, Pedersen NO, Lomholt N. Prevention of silent aspiration due to leaks around cuffs of endotracheal tubes. AnesthAnalg 1986; 65:777-780.

19. Young PJ, Rollinson M, Downward G, Henderson S. Leakage of fluid past the tracheal tube cuff in a benchtop model. Br J Anaesth 1997; 78:557-562.

20. MahulPh, Auboyer C, Jospe R, Ros A, Guerin C, El Khouri Z et al. Prevention of nosocomial pneumonia in intubated patients: respective role of mechanical subglottic secretions drainage and stress ulcer prophylaxis. Intensive Care Med 1992; 18:20-25.

21. Smulders K, van der Hoeven H, Weers-Pothoff I, Vandenbroucke-Grauls C. A randomized clinical trial of intermittent subglottic secretion drainage in patients receiving mechanical ventilation. Chest 2002; 121:858-862.

22. Kollef MH, Skubas NJ, Sundt TM. A randomized clinical trial of continuous aspiration of subglottic secretions in cardiac surgery patients. Chest 1999; 116:1339-1346.

23. Valles J, Artigas A, Rello J, Bonsoms N, Fontanals D, Blanch L et al. Continuous aspiration of subglottic secretions in preventing ventilator-associated pneumonia. Ann Intern Med 1995; 122:179-186. 
24. Dezfulian C, Shojania K, Collard HR, Kim HM, Matthay MA, Saint S. Subglottic secretion drainage for preventing ventilator-associated pneumonia: a meta-analysis. Am J Med 2005; 118:11-18.

25. Dezfulian C, Shojania K, Collard HR, Kim HM, Matthay MA, Saint S. Subglottic secretion drainage for preventing ventilator-associated pneumonia: a meta-analysis. Am J Med 2005; 118:11-18.

26. Lorente L, Lecuona M, Jimenez A, Mora ML, Sierra A. Influence of an endotracheal tube with polyurethane cuff and subglottic drainage on pneumonia. Am J RespirCrit Care Med 2007; 176:1079-1083.

27. Bo H, He L, Qu J. Influence of the subglottic secretion drainage on the morbidity of ventilator associated pneumonia in mechanically ventilated patients. Zhonghua Jiehe he hu xi za zhi 2000; 23 : 472-474.
28. Seegobin RD, van Hasselt GL. Aspiration beyond endotracheal cuffs. Can AnaesthSoc J 1986;33:273-279.

29. Pavlin EG, VanNimwegan D, Hornbein TF. Failure of a high-compliance low-pressure cuff to prevent aspiration. Anesthesiology 1975;42:216-219.

30. Lewis FR Jr, Schiobohm RM, Thomas AN. Prevention of complications from prolonged tracheal intubation. Am J Surg 1978; 135: $452-457$.

31. Black AM, Seegobin RD. Pressures on endotracheal tube cuffs. Anaesthesia 1981; 36: 498-511. 
